\title{
Low temperature Fourier transform infrared spectra and hydrogen bonding in polycrystalline uracil and thymine
}

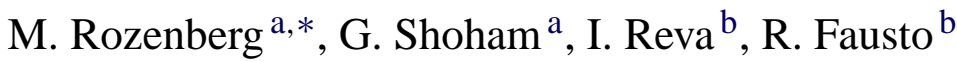 \\ ${ }^{a}$ Department of Inorganic and Analytical Chemistry, The Hebrew University of Jerusalem, Givat Ram, Jerusalem 91904, Israel \\ ${ }^{\mathrm{b}}$ Department of Chemistry, University of Coimbra, 3004-535 Coimbra, Portugal
}

Received 15 October 2003; accepted 8 December 2003

\begin{abstract}
The FTIR spectra of pure $\mathrm{NH}$ and isotopically diluted (NH/ND and ND/NH) polycrystalline uracil and thymine were measured in the range $4000-400 \mathrm{~cm}^{-1}$ at temperatures from 300 to $10 \mathrm{~K}$. For the first time, the essentially narrow bands corresponding to the uncoupled stretching $\left(v_{1}\right)$ and out of plane bending $\left(v_{4}\right) \mathrm{NH}$ proton modes of uracil and thymine were observed in the solid phase. It was found that in the $v_{4}$ region the spectra reveal more details on the H-bond interactions present in both solids than in the $v_{1}$ range. The frequencies of the various bands observed in both spectral regions were used for estimation of the H-bond energy, using empirical correlations between this property and both the red shift of $v_{1}$ and the blue shift of $v_{4}$ that occur upon crystallization due to the establishment of the H-bonds. The results are compared with known thermodynamic, structural and theoretical data. The IR data also suggest that the H-bond networks of both crystals contain, besides the two $\mathrm{NH} \cdots \mathrm{O}=\mathrm{C}$ bonds revealed by $\mathrm{X}$-ray experiments, additional types of $\mathrm{H}$-bonds, which do not show long range periodicity and, thus, cannot be detected by the conventional structural methods. The assignment of some other bands in the spectra of both substances was also reviewed. (C) 2003 Elsevier B.V. All rights reserved.
\end{abstract}

Keywords: Uracil; Thymine; H-bonding in solids; Low temperature FTIR spectra; Isotopic dilution

\section{Introduction}

This paper is part of a series where an approach based on the concerted use of low temperature FTIR spectroscopy and isotopic dilution techniques has been applied to the study of hydrogen bonding in crystalline networks of biological interest. The general approach used was formulated recently $[1,2]$ and the previous results unequivocally demonstrate the existence of non-negligible $\mathrm{H}$-bonding disorder in crystalline nucleosides [1], carbohydrates [3,4], L-alanine [5] and cytosine [6,7], which cannot be probed using standard structural methods (e.g., X-ray diffraction).

The main advantages of the methodology here used result essentially from the fact that the broadening generally observed in the bands originated in both the stretching $\left(v_{1}\right)$ and out of plane bending $\left(v_{4}\right)$ proton modes, which result from the interaction of these modes with thermally excited low frequency intermolecular librations, is suppressed at $T<$ $30 \mathrm{~K}$, leading to a considerable increase in the spectral reso-

\footnotetext{
* Corresponding author. Tel.: +972-26585177; fax: +972-26585319.

E-mail address: markroz@chem.ch.huji.ac.il (M. Rozenberg).
}

lution. In addition, isotopic dilution provides a way to decouple individual proton modes, enabling the direct observation of bands originated in a particular proton vibration, which under normal conditions is coupled to vibrational modes of symmetrically equivalent protons [1]. As a result, under the conditions described the typical bandwidths of $v_{1}$ and $v_{4}$ bands decrease from hundreds to tens of wavenumbers, new details in the spectra become visible and the parameters of these bands can be measured with high accuracy.

In the present paper, the IR spectra of uracil and thymine were examined using the experimental conditions described above briefly. Particular emphasis is given to the analysis of the stretching and out of plane bending $\mathrm{NH}$ proton mode bands.

The atom numbering schemes used in this paper for the two molecules under analysis are shown on Fig. 1. Despite both uracil and thymine are constituents of nucleic acids and have attracted considerable interest in the past, the number of studies dealing with their hydrogen bonding structures in the crystalline phase is relatively scarce [8-11]. From X-ray diffraction experiments, it is known that the differences between hydrogen bond contacts in 

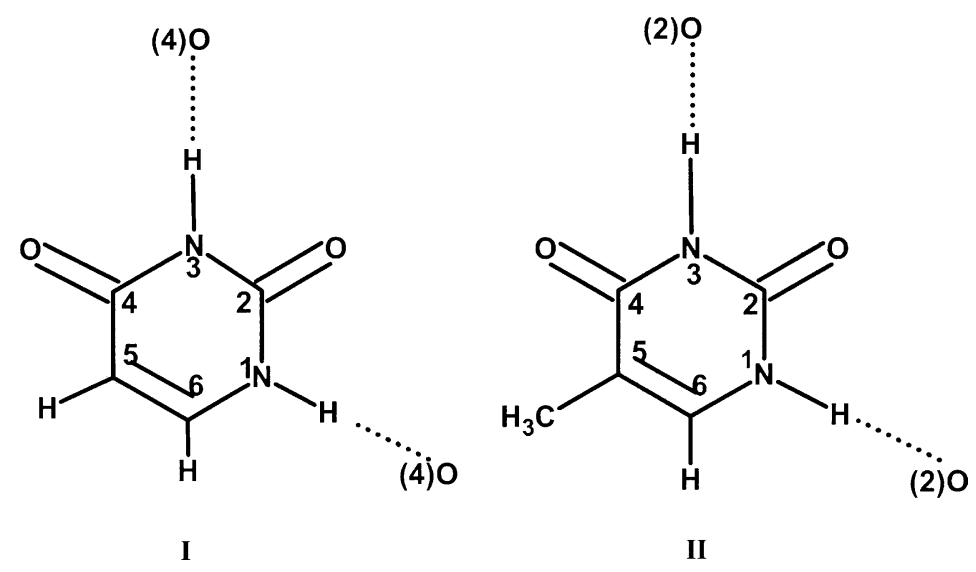

Fig. 1. Chemical structure and atom numbering of uracil (I) and thymine (II).

the crystals of the two compounds are relatively small. The two compounds were found to exist, in crystals, exclusively in their diimino-diketo tautomer [8-11]. Uracil forms centrosymmetric dimers through $\mathrm{N} 3-\mathrm{H} \cdots \mathrm{O}=\mathrm{C}^{\prime}$ linkages (with $\mathrm{N} 3 \cdots \mathrm{O}$ distances of $0.2865 \mathrm{~nm}$ ), which are connected by additional bifurcated $\mathrm{H}$-bonds involving the $\mathrm{N} 1-\mathrm{H}$ and $\mathrm{O}=\mathrm{C} 4$ groups and identical partners from neighbor molecules (with $\mathrm{N} 1 \cdots \mathrm{O}$ distances equal to $0.2864 \mathrm{~nm}$ ) $[9,10]$. The $\mathrm{O}=\mathrm{C} 2$ carbonyl group is involved in two weaker $\mathrm{C}-\mathrm{H}^{\prime} \ldots \mathrm{O}=\mathrm{C} 2$ interactions (the symbol $\left({ }^{\prime}\right)$ was here used to distinguish different molecules). For thymine, similar cyclic dimers with $\mathrm{N} 3-\mathrm{H}^{\prime} \ldots \mathrm{O}=\mathrm{C}^{\prime}$ and $\mathrm{N} 1-\mathrm{H} \cdots \mathrm{O}=\mathrm{C} 2$ hydrogen bond contacts of 0.2810 and $0.2836 \mathrm{~nm}$, respectively, were found to constitute the main structural unit of the crystal $[10,11]$. The most interesting features to stress here are (i) the fact that in the X-ray structures of both crystals each one of the $\mathrm{N} 1-\mathrm{H}$ and $\mathrm{N} 3-\mathrm{H}$ groups participates in a single type of $\mathrm{H}$-bond, with a well defined characteristic distance, (ii) the observation that the dimers in uracil are made by H-bonds connecting $\mathrm{N} 3$ of one molecule to the $\mathrm{O}=\mathrm{C} 4$ group of the other, while in thymine dimers the acceptor carbonyl group is $\mathrm{O}=\mathrm{C} 2$ in both molecules but the donor atom is N1 in one molecule and N3 in the other (in this case, the dimers are not centrosymmetric).

Uracil and thymine were also studied previously by FTIR and Raman spectroscopy methods. Both compounds were studied as free molecules in the gaseous phase [12] and inert gas matrices [13-20]. They were also studied in the crystalline phase, both at room and low temperatures [15,21-23]. The assignment of the observed bands has been, in some cases, supported by theoretical predictions of the vibrational spectra for the isolated molecules [24,25] or for the crystal state $[21,22,26]$. In this latter case, the vibrational frequencies calculated for single molecules were afterwards empirically adjusted in order to fit the experimental data.

One important conclusion from previous spectroscopic studies on uracil and thymine refers to hydrogen bonding and can be synthesized using words from [18]: “...the intermolecular forces in the solid have a profound effect on the appearance of the IR spectrum, such that correspondence between the bands observed in the solid and those observed here for the isolated molecules is not obvious". This conclusion stressed the interest of using IR spectroscopy together with specifically designed sampling techniques, as isotopic dilution, to further elucidate the details of the hydrogen bonding networks in the crystals of the two compounds.

As mentioned before, in the present study, to overcome the well-known difficulties to estimate the peak positions of the usually very broad $v_{1}$ and $v_{4}$ bands and assign their different components, we took advantage of using isotopically doped crystals and low temperatures. The spectral changes were followed as a function of temperature, within the range $10-300 \mathrm{~K}$.

\section{Experimental}

The IR spectra of polycrystalline pure NH- (Sigma), $\approx 5 \%$ ND- and $80-85 \%$ ND-uracil (or thymine) in a $\operatorname{KBr}(1: 200)$ disc, attached to the cold finger of an APD Cryogenics closed-cycle helium refrigeration system with a DE-202A expander, were recorded with a Mattson Infinity 60AR series FTIR spectrometer, with spectral resolution of $1 \mathrm{~cm}^{-1}$. The temperature $(10-300 \mathrm{~K})$ was measured directly at the sample holder by a silicon diode temperature sensor connected to a Lake Shore Cryogenics temperature controller (model DRC-91CA). The sample temperature during registration of spectra was kept stable within $0.2 \mathrm{~K}$. The temperatureinduced spectral changes observed for all substances were found to be reversible and highly reproducible. Deuterated samples were obtained from commercial uracil (thymine) by repetitive exchange with $\mathrm{D}_{2} \mathrm{O}$ (Aldrich) in recirculating cyclohexane at $81^{\circ} \mathrm{C}$, as described in [27].

\section{Results and discussion}

In this study we are particularly interested to look at the temperature and isotopic shift effects on the $\mathrm{NH}$ proton modes. Hence, experimental conditions were chosen so that 


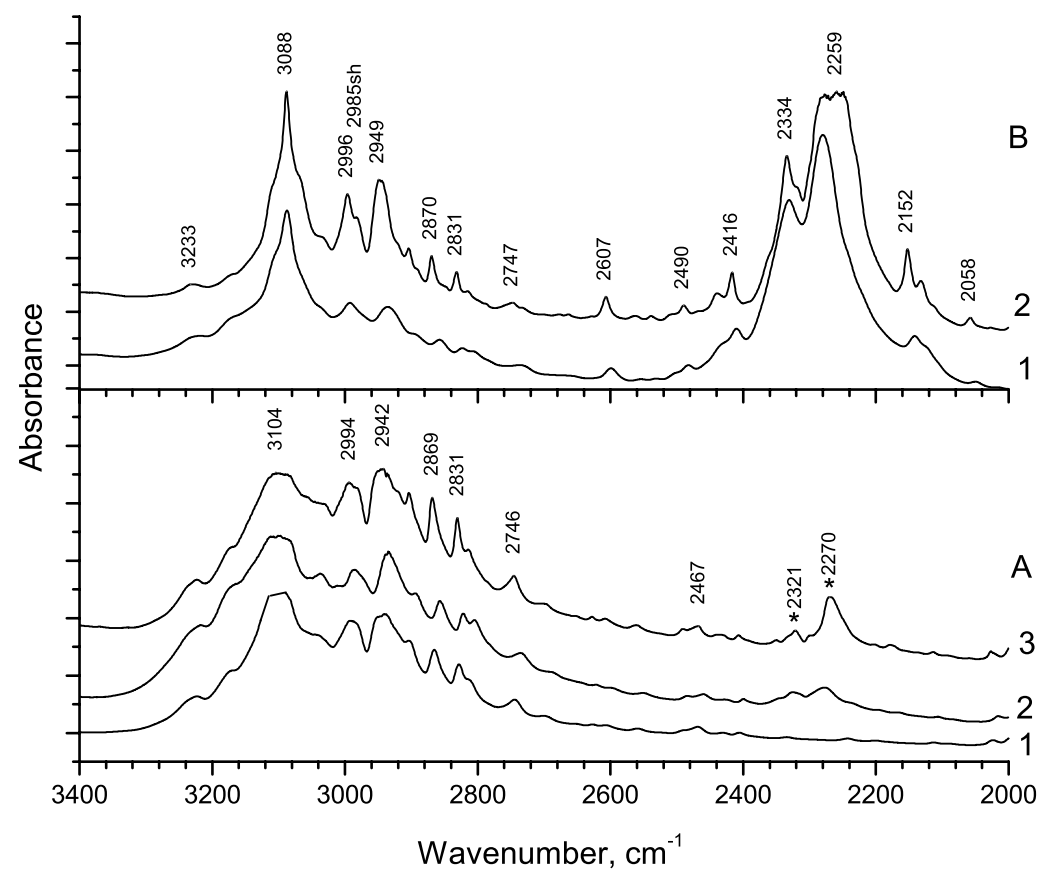

Fig. 2. FTIR spectra of uracil in the $\mathrm{NH}$ and $\mathrm{CH}$ stretching spectral region: (A) 1-100\% NH at 300 K; 2-95\% NH at 300 K; 3-95\% NH at $10 \mathrm{~K}$; (*) bands of ND doped groups; and (B) $1-15 \% \mathrm{NH}$ at $300 \mathrm{~K} ; 2-15 \% \mathrm{NH}$ at $10 \mathrm{~K}$.

they were optimized to examine the usually very weak bands originated in the isotopically doped molecules appearing in the $3400-2000 \mathrm{~cm}^{-1}$ spectral range and below $1550 \mathrm{~cm}^{-1}$. On the contrary, the spectral range $1700-1550 \mathrm{~cm}^{-1}$, where very intense bands of uracil and thymine are observed (mainly $\nu \mathrm{C}=\mathrm{O}$ and $\nu \mathrm{C}=\mathrm{C}$ bands), has been studied in a multitude of previous works and will not be discussed in detail here.

\subsection{Spectral assignments}

\subsection{1. $3400-2000 \mathrm{~cm}^{-1}$ spectral range: the $\mathrm{NH}$ and $\mathrm{CH}$ stretching vibrations}

3.1.1.1. Uracil. The spectra of polycrystalline uracil samples in the $3400-2000 \mathrm{~cm}^{-1}$ region are shown in Fig. 2. Fig. 2A shows the spectra of the pure NH compound (trace 1 ) and of the ca. 5\% ND doped crystal (traces 2 and 3, obtained at 300 and $10 \mathrm{~K}$, respectively); Fig. 2B presents the spectra of the ca. 85\% ND containing crystal (traces 1 and 2 correspond to $T=300$ and $10 \mathrm{~K}$, respectively).

From Fig. 2A (traces 2 and 3), it can be concluded that the very broad and complex band appearing in the $3400-2500 \mathrm{~cm}^{-1}$ region, whose intensity predominantly originates in the $v \mathrm{NH}$ stretching modes of samples with an $\mathrm{NH}$ concentration close to $100 \%$, does not change significantly upon cooling. The main observed effect of lowering the temperature is the usual narrowing effect that leads to a slightly better resolved band structure. The same behavior is essentially observed for the ND bands of the $85 \%$ ND containing crystal of uracil shown in Fig. 2B, though in this case the main peak (observed at $2270 \mathrm{~cm}^{-1}$ in the spectrum at room temperature) shows a noticeable red shift upon cooling. On the other hand, the bands originated in the isotopically doped molecules (both in the 5\% ND and $15 \% \mathrm{NH}$ doped crystals), which are, as expected, relatively narrow, show small but remarkable temperature changes. These changes are particularly evident in the case of the bands due to the ND containing molecules in the 5\% ND doped crystal (see Fig. 2A, traces 2 and 3), which appear in a clear spectral region.

The strong differences between the NH or ND stretching band profiles originated in the dominant isotopic species (compare the $3400-2500 \mathrm{~cm}^{-1} \mathrm{NH}$ stretching region in Fig. 2A with the $2400-2000 \mathrm{~cm}^{-1}$ ND stretching region in Fig. 2B) clearly indicate that the structures exhibited by these bands result mainly from resonant interactions. Resonance interactions involving overtones of the $\mathrm{NH}$ or ND bending modes are also observed in the case of bands due to the minor species in the doped crystals. The temperature dependence of the relevant spectral regions is shown with more detail in Fig. 3.

In the case where the $\mathrm{NH}$ containing molecules are the minor species present in the crystal (Fig. 3A), the bands observed at 2993 and $2936 \mathrm{~cm}^{-1}$ at $300 \mathrm{~K}$ experience blueshifts upon cooling. These bands can be assigned to the overtones of the $\mathrm{NH}$ in-plane bending modes, which are strengthened by resonance interactions with the $v_{1}(\mathrm{~N} 3 \mathrm{H})$ stretching mode and whose fundamentals are observed at 1516 and $1463 \mathrm{~cm}^{-1}$ (see Fig. 4). The feature with absolute maximum at $3088 \mathrm{~cm}^{-1}$ has at least three components: the narrow component at $3088 \mathrm{~cm}^{-1}$, that does not change its 

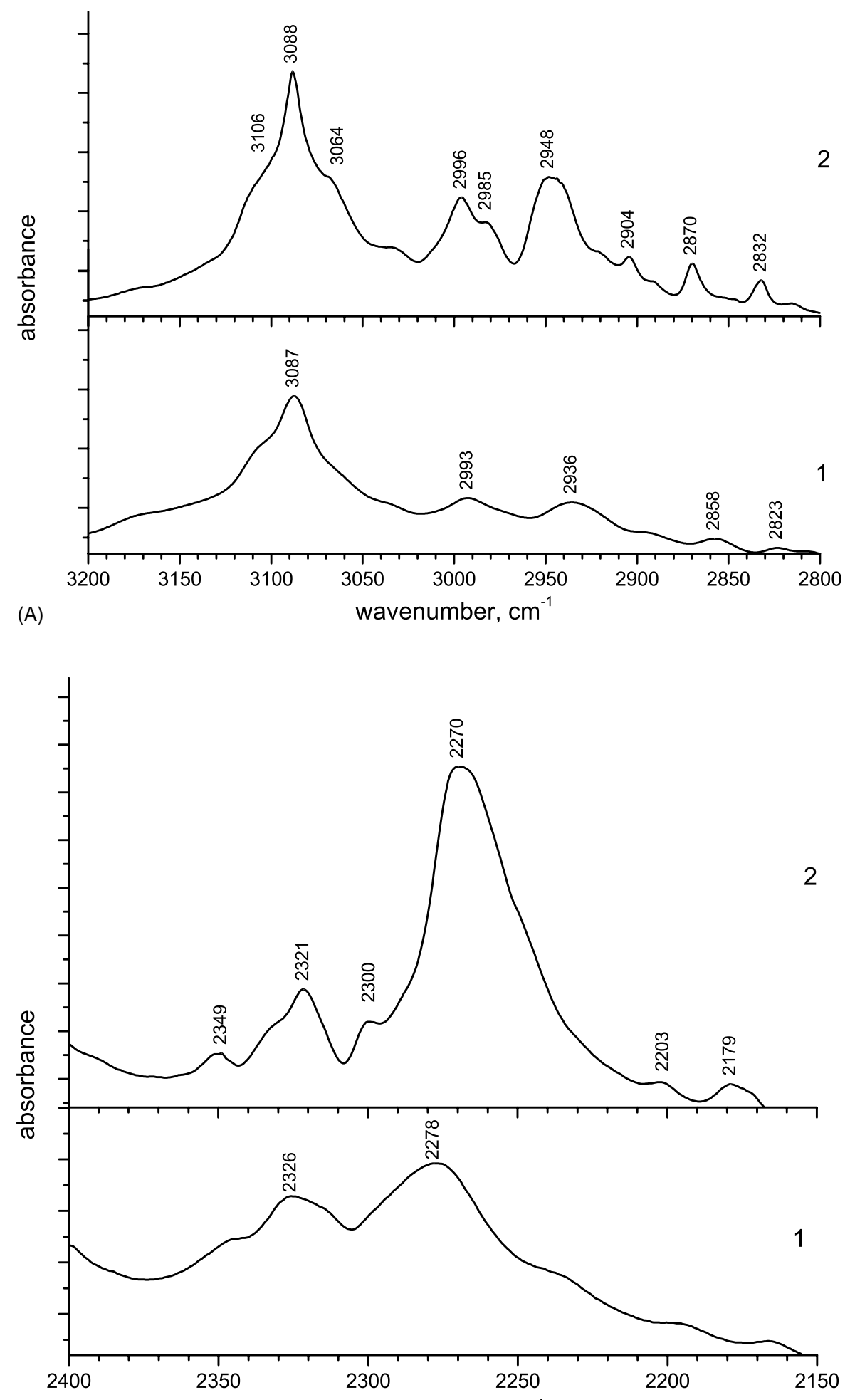

(B)

wavenumber, $\mathrm{cm}^{-1}$

Fig. 3. Expansion of the $\mathrm{NH}$ and $\mathrm{CH}$ stretching spectral region: (A) $v_{1} \mathrm{NH}$ bands in the spectrum of mostly ND-uracil; 1-spectrum obtained at $300 \mathrm{~K}$; 2-spectrum obtained at $10 \mathrm{~K}$; and (B) $v_{1} \mathrm{ND}$ bands in the spectrum of mostly $\mathrm{NH}$-uracil; 1 -spectrum obtained at $300 \mathrm{~K}$; 2 -spectrum obtained at $10 \mathrm{~K}$.

frequency and intensity upon cooling and shows a slight decrease in its bandwidth, corresponds to the $\mathrm{CH}$ antisymmetric stretching mode with controversial assignment to $\mathrm{C} 6 \mathrm{H}$ [20] or to $\mathrm{C} 5 \mathrm{H}$ [24]; the highest frequency compo- nent, at $3106 \mathrm{~cm}^{-1}$, which does not change in position and bandwidth but increases its intensity by ca. $60 \%$ on cooling, is ascribable to the $v_{1}(\mathrm{~N} 1 \mathrm{H})$ stretching mode; finally, the lowest frequency component, at $3064 \mathrm{~cm}^{-1}$, red shifts by 
$4 \mathrm{~cm}^{-1}$, reduces its bandwidth (by ca. $10 \%$ ) and intensifies (approximately two times), corresponding to an additional component of the whole set of bands resulting from resonant interactions involving the $v_{1}(\mathrm{~N} 3 \mathrm{H})$ mode (as mentioned above, other bands resulting from this interaction are observed at 2993 and $2936 \mathrm{~cm}^{-1}$ ). Since the inherent overtone intensity involved in the resonant interaction with $v_{1}(\mathrm{~N} 3 \mathrm{H})$ should be small, all three components shall be essentially described as $v_{1}(\mathrm{~N} 3 \mathrm{H})$ bands; the frequency of the gravity center for this set of bands is then ca. $3000 \mathrm{~cm}^{-1}$. Note that the assignments here proposed indicate a larger relative IR intensity for the $v_{1}(\mathrm{~N} 3 \mathrm{H})$ mode than for $v_{1}(\mathrm{~N} 1 \mathrm{H})$. Hence, both relative frequencies and IR intensities of $v_{1}(\mathrm{~N} 3 \mathrm{H})$ and $v_{1}(\mathrm{~N} 1 \mathrm{H})$ indicate that the first group is involved in stronger $\mathrm{H}$-bond interactions in crystalline uracil (it is well known that the intensity of the proton stretching vibrations of the groups involved in hydrogen bonding increases with the strength of the interaction [28]). The larger red shift observed for the $v_{1}(\mathrm{~N} 3 \mathrm{H})$ mode relatively to its frequency for the matrix isolated uracil molecule when compared with the shift observed for $v_{1}(\mathrm{~N} 1 \mathrm{H}): 423$ versus $364 \mathrm{~cm}^{-1}$ (taking as reference results obtained in a $\mathrm{N}_{2}$ matrix [15]) or 433 versus 376 (using data obtained for the molecule in an $\mathrm{Ar}$ matrix [20]), is also consistent with a stronger H-bonding in $\mathrm{N} 3 \mathrm{H}$ than in $\mathrm{N} 1 \mathrm{H}$.

The results are clearly more difficult to interpret in the case where the ND containing molecules are the minor species present in the crystal (Fig. 3B). Indeed, in this case the assignment of the observed bands to the $v_{1}$ (N3D) and $v_{1}$
(N1D) modes could not be unequivocally undertaken. The observed band profile consists essentially of two components, each one formed by several overlapping bands: the first component stays between 2370 and $2300 \mathrm{~cm}^{-1}$, and the second component comprehends the region between 2300 and ca. $2200 \mathrm{~cm}^{-1}$. At cooling, the intensity ratio of the two components changes from $1: 2$, at $300 \mathrm{~K}$, to ca. $1: 5$ at $10 \mathrm{~K}$. A possible interpretation for, at least, part of this change in the relative intensities, suggests that $v_{1}$ (N1D) and $v_{1}$ (N3D) contribute mainly to the higher frequency and lower frequency set of bands in this region, respectively; the strength of the $v_{1}(\mathrm{~N} 3 \mathrm{D}) \mathrm{H}$-bond increases in a greater extension with the decrease in temperature than that involving $v_{1}$ (N1D); accordingly, the low frequency/high frequency region intensity ratio also decreases. Note that this tentative assignment of the $v_{1}(\mathrm{~N} 1 \mathrm{D})$ and $v_{1}(\mathrm{~N} 3 \mathrm{D})$ modes to the high and low frequency set of components in this spectral region leads to isotopic shifts of ca. 1.33 for both vibrations, which are identical to those previously observed for alanine and cytosine vibrations $[5,6]$. Another phenomenon that may also contribute to the observed change in the relative intensity of the two main components found in this spectral region involves resonance interactions of $v_{1}$ (N3D) with the overtone of the ND in-plane bending mode (whose fundamental is observed at $1147 \mathrm{~cm}^{-1}$ _ see Fig. 4, trace 3). This resonance is expected to be sharper at $300 \mathrm{~K}$ (leading to a larger distribution of intensity between the two components), while, on cooling, the overtone moves upwards and the $v_{1}$ (N3D) band moves downwards in frequency, weakening the resonance

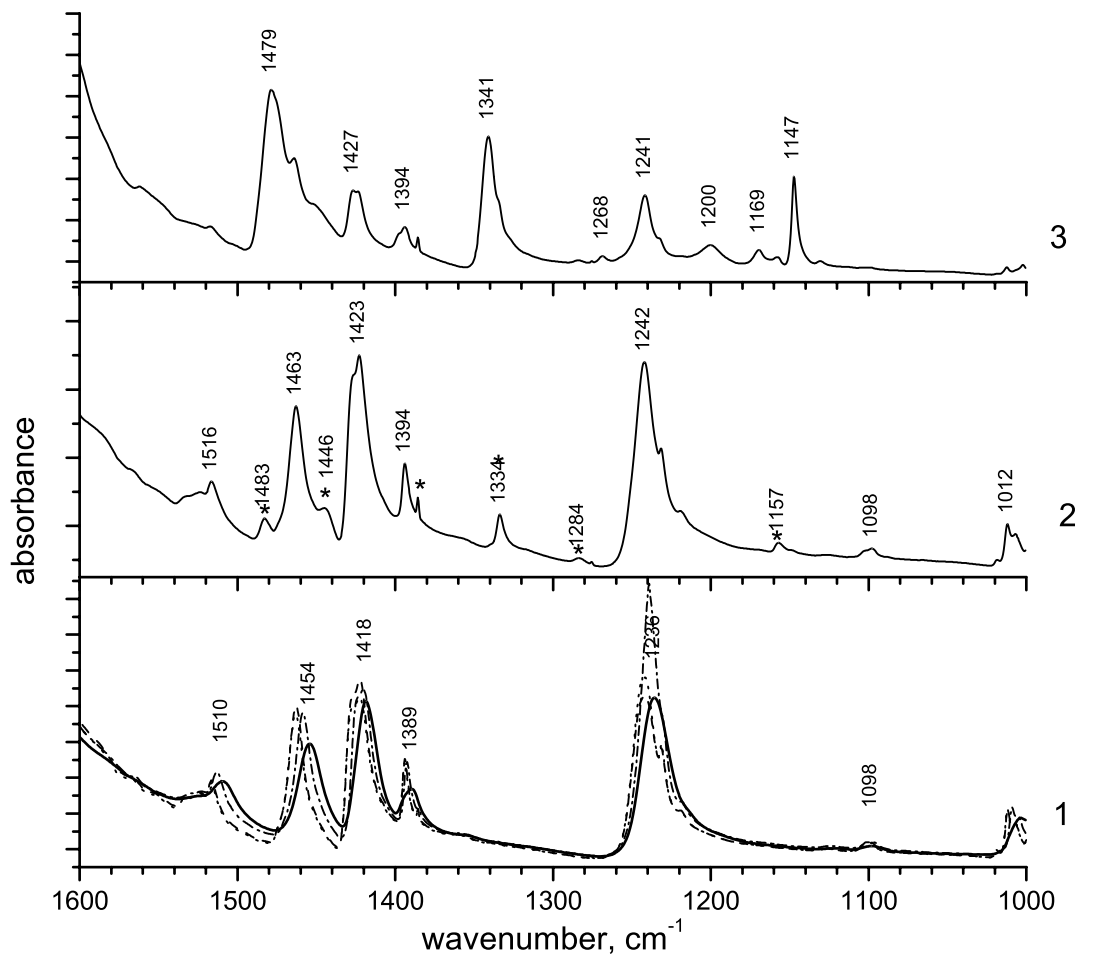

Fig. 4. FTIR spectra of uracil in the NH in-plane bending spectral region: 1-100\% NH at $300 \mathrm{~K}$-solid; $200 \mathrm{~K}$-dash-dots; $100 \mathrm{~K}$-dashes; and $10 \mathrm{~K}-$ dots; peak positions correspond to $300 \mathrm{~K}$ spectrum; 2-95\% NH at $10 \mathrm{~K} ;(*)$ bands of doped ND groups; $3-15 \% \mathrm{NH}$ at $10 \mathrm{~K}$. 
conditions and considerably reducing the amount of intensity transferred from the $v_{1}$ (N3D) fundamental to the ND bending overtone, thus leading to the observed decrease in the intensity ratio.

As mentioned before, the band observed at $3088 \mathrm{~cm}^{-1}$ in the spectra of the $15 \% \mathrm{NH}$ containing crystal corresponds to the $\mathrm{CH}$ antisymmetric stretching vibration. In the Raman spectrum of the uracil monomer isolated in an Ar matrix, the corresponding band was observed at $3084 \mathrm{~cm}^{-1}$ [15]. Note that in the IR spectrum of pure NH crystalline sample this band is observed only as a shoulder of the intense band at $3104 \mathrm{~cm}^{-1}$, which integrates the complex band profile due to the coupled NH stretching vibrations (see Fig. 2A). The $\mathrm{CH}$ symmetric stretching mode (that has a larger contribution from $\mathrm{C} 6 \mathrm{H}$ [12]) is here tentatively ascribed to the shoulder at $2985 \mathrm{~cm}^{-1}$, which is clearly observed only at $10 \mathrm{~K}$ (see Fig. 3A, trace 2). The assignment of this mode has been the subject of great controversy in the past [12,15,21-23]. However, in consonance with the present assignment, in thymine, where due to the H-by-methyl substitution at the $\mathrm{C} 5$ position the coupling between the two individual $\mathrm{CH}$ stretching modes can no more operate, the $\mathrm{CH}$ stretching mode is observed at $3061 \mathrm{~cm}^{-1}$, i.e., at nearly the average position of the two bands now assigned to the $\mathrm{CH}$ stretching modes in uracil.

3.1.1.2. Thymine. The spectra of polycrystalline $\mathrm{NH}$ and ND thymine obtained at 300 and $10 \mathrm{~K}$ (Fig. 5) are similar to the previously reported $[18,26,29]$. However, the NH/CH stretching region of isotopically diluted thymine cooled down to $10 \mathrm{~K}$ became considerably more informative than those of isotopically pure crystals. First of all, the band at $3061 \mathrm{~cm}^{-1}$ becomes well-resolved (Fig. 5B) and can be easily assigned to the $\mathrm{C} 6 \mathrm{H}$ stretching mode, in agreement

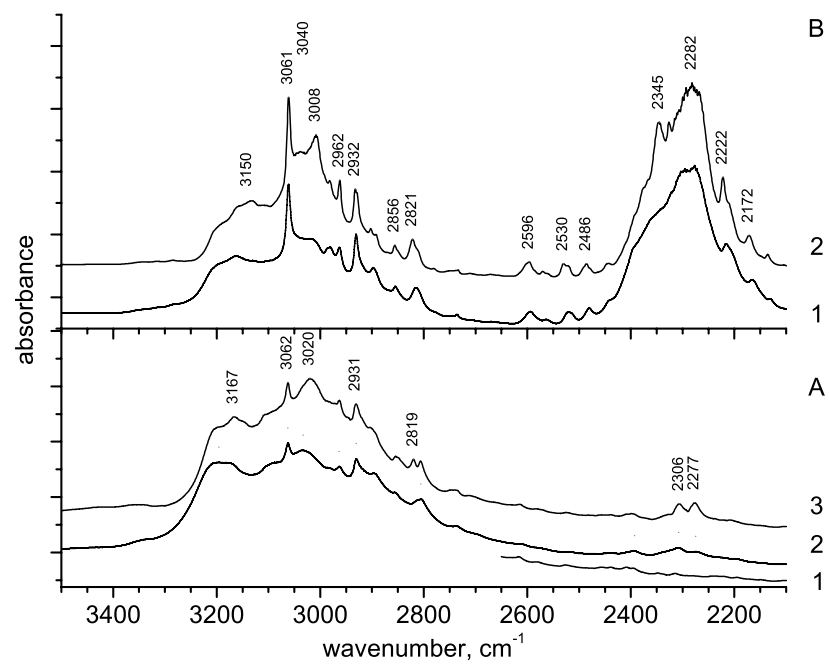

Fig. 5. FTIR spectra of thymine in the $\mathrm{NH}$ and $\mathrm{CH}$ stretching spectral region: (A) $1-100 \% \mathrm{NH}$ at $10 \mathrm{~K}$, for simplicity, only the absence of any bands below $2600 \mathrm{~cm}^{-1}$ is shown (above this frequency the spectrum is identical to that shown on trace 2); $2-95 \% \mathrm{NH}$ at $300 \mathrm{~K} ; 3-95 \% \mathrm{NH}$ at $10 \mathrm{~K}$; and (B) $1-20 \% \mathrm{NH}$ at $300 \mathrm{~K} ; 2-20 \% \mathrm{NH}$ at $10 \mathrm{~K}$. with [29]. In addition, the bands at 2962 and $2932 \mathrm{~cm}^{-1}$, which can be also clearly observed in the spectrum of the $\mathrm{NH}$ doped deuterated crystal and were found to be insensitive to the temperature change, can be now unequivocally assigned respectively to the antisymmetric (two modes) and symmetric stretching vibrations of the $\mathrm{CH}_{3}$ group.

The band at $3008 \mathrm{~cm}^{-1}$, which was not reported before-it becomes clear only at low temperature and for the isotopically diluted crystal (see Fig. 5) - is here assigned to one of the uncoupled $\mathrm{NH}$ stretching modes, while the band at $3040 \mathrm{~cm}^{-1}$ is ascribed to the second $\mathrm{NH}$ uncoupled stretching mode. Taking into consideration the calculated data reported in [22], the higher frequency band should be ascribed to the $\mathrm{N} 1 \mathrm{H}$ stretching mode, whereas the lower frequency band shall be due to the $\mathrm{N} 3 \mathrm{H}$ stretching vibration. The intense set of bands appearing above ca. $3100 \mathrm{~cm}^{-1}$ in the spectra of the crystals where $\mathrm{NH}$ containing species are dominant (see Fig. 5A), becomes weaker upon deuterium exchange (Fig. 5B) and results from the vibrational coupling involving $\mathrm{NH}$ groups taking part in multiple $\mathrm{H}$ bonds and low frequency lattice vibrations. Indeed, when the concentration of $\mathrm{NH}$ groups in the sample is below ca. $10 \%$, as in the case of the data shown in [29], these bands were not observed. In the spectra of the crystal where the concentration of the ND containing thymine is only ca. 5\%, a doublet with components at 2306 and $2277 \mathrm{~cm}^{-1}$ can be clearly seen at $10 \mathrm{~K}$ (Fig. 5A, trace 3 ). This doublet reveals a clear temperature dependence (compare traces 2 and 3 in Fig. 5A) and its higher and lower components are assigned to N1D and N3D stretching modes, respectively. Note that this assignment leads to an isotopic frequency ratio for both $\mathrm{N} 1 \mathrm{H}$ and $\mathrm{N} 3 \mathrm{H} v_{1}$ modes of thymine close to 1.32 , and is similar to that observed in uracil.

\subsection{2. $1550-1000 \mathrm{~cm}^{-1}$ spectral range: the $\mathrm{NH}$ and $\mathrm{CH}$ in-plane bending vibrations}

3.1.2.1. Uracil. The IR spectrum of the $100 \% \mathrm{NH}$ uracil at different temperatures, in the $1550-1000 \mathrm{~cm}^{-1}$ spectral range, is shown in Fig. 4 (frame 1) together with that of the ND doped (trace 2 ) and $\mathrm{NH}$ doped (trace 3 ) crystals at $10 \mathrm{~K}$. The data shown in Fig. 4 reveal that the spectrum of uracil in this spectral range is relatively simple at room temperature, showing essentially five bands. From those, only the weak band at $1394 \mathrm{~cm}^{-1}$ does not change its peak position and intensity with temperature and deuterium exchange. Its behavior upon temperature variation and isotopic substitution confirms its assignment to a skeletal ring or $\mathrm{CH}$ mode. On the other hand, the bands at 1516,1463,1423, and $1242 \mathrm{~cm}^{-1}$ (at $300 \mathrm{~K}$ ) show significant blue shifts or/and narrowing at cooling, and become weaker at deuterium exchange; they shall be related to vibrational modes with relevant contribution of NH proton modes. In agreement with our conclusion, the calculations made in [21] for solid $(15 \mathrm{~K})$ uracil predicted that the PED contributions of $\mathrm{NH}$ modes to the 1516 and $1423 \mathrm{~cm}^{-1}$ bands should be ca. $30 \%(\delta \mathrm{N} 1 \mathrm{H})$ and 


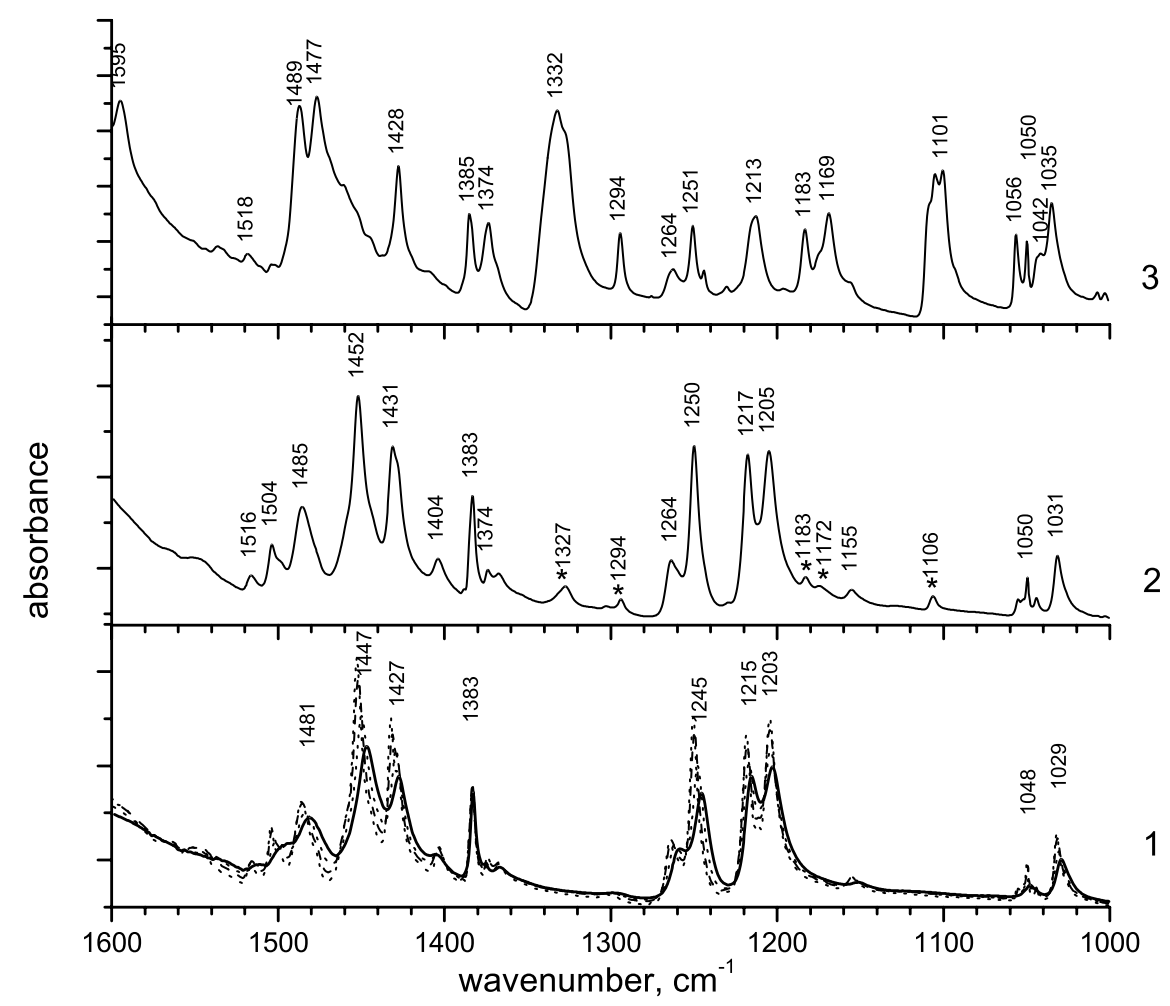

Fig. 6. FTIR spectra of thymine in the NH in-plane bending spectral region: $1-100 \% \mathrm{NH}$ at $300 \mathrm{~K}$-solid; $200 \mathrm{~K}$-dash-dots; $100 \mathrm{~K}-$ dashes; and $10 \mathrm{~K}$-dots; peak positions correspond to $300 \mathrm{~K}$ spectrum; $2-95 \% \mathrm{NH}$ at $10 \mathrm{~K} ;(*)$ bands of doped ND groups; 3-20\% NH at $10 \mathrm{~K}$.

ca. $50 \%(\delta \mathrm{N} 3 \mathrm{H})$. However, those calculations seem to underestimate the involvement of the $\mathrm{NH}$ in-plane bending coordinates to the vibrations that give rise to the bands at 1463 and $1242 \mathrm{~cm}^{-1}$, predicting contributions of the $\mathrm{NH}$ in-plane bending coordinates for these vibrations below $6 \%$.

3.1.2.2. Thymine. The $1550-1000 \mathrm{~cm}^{-1}$ spectral range of the IR spectrum of $100 \% \mathrm{NH}$ thymine at different temperatures is presented in Fig. 6 (frame 1), together with those of the NH and ND doped samples at $10 \mathrm{~K}$ (traces 2 and 3, respectively). When used together, cooling and deuteration experiments reveal the bands that are not particularly sensitive to both temperature and isotopic changes. These are the weak bands observed at 1383,1264, 1217, 1155, 1050, and $1031 \mathrm{~cm}^{-1}$ in the room temperature spectrum of the pure NH crystal. Their behavior confirms their assignment to $\mathrm{CH}_{3}$ or $\mathrm{CH}$ bending or skeletal (ring stretching) modes [29]. The band at $1431 \mathrm{~cm}^{-1}$ is relatively more sensitive to temperature variation but it is not affected by deuteration and should also be assigned to a $\mathrm{CH}_{3} / \mathrm{CH}$ bending or skeletal mode. All other bands show noticeable temperature changes and all of them almost disappear at D-exchange (compare traces 1 and 3 of Fig. 6). There are in the spectrum of NH-thymine at least seven bands, namely at 1516 , $1504,1485,1452,1404,1250$, and $1205 \mathrm{~cm}^{-1}$, which are affected by cooling and D-exchange. In agreement with [29], we ascribe the intense band at $1452 \mathrm{~cm}^{-1}$ to a vibration with major contribution from the $\mathrm{N} 1 \mathrm{H}$ in-plane bending coordi- nate. The assignment of the remaining bands is more difficult, though all of them should have relevant contributions from the $\mathrm{NH}$ in-plane bending coordinates. In the spectrum of 5\% ND doped thymine (Fig. 6, trace 2) new very weak bands due to vibrations of the ND groups appear at 1327 , $1294,1183,1169$, and $1106 \mathrm{~cm}^{-1}$. The intensities of these new bands increase in the spectrum of the mostly ND-crystal (Fig. 6, trace 3), where additional new bands are also observed at 1489, 1477, 1374, 1056, and $1042 \mathrm{~cm}^{-1}$. Among all those bands, that observed at $1169 \mathrm{~cm}^{-1}$ shows the most noticeable temperature narrowing effect and appears as the best candidate for being originated in the vibration with the largest contribution from the N3D in-plane bending coordinate. The corresponding vibration in the non-deuterated species should then be tentatively ascribed to the band observed at $1485 \mathrm{~cm}^{-1}$, the isotopic frequency ratio for this mode being ca. 1.27 (the $1485 \mathrm{~cm}^{-1}$ band also exhibits the proton mode characteristic blue shift on cooling).

\subsection{3. $1000-400 \mathrm{~cm}^{-1}$ spectral range: the NH out of plane bending vibrations}

3.1.3.1. Uracil. The $1000-400 \mathrm{~cm}^{-1}$ region of the spectrum of pure $\mathrm{NH}$ uracil at different temperatures is presented in Fig. 7 (frame 1). The corresponding spectra of ND and $\mathrm{NH}$ doped samples are presented in the same figure (traces 2 and 3 ) for comparison. In general, in this region the spectra are similar to those previously measured $[21,30]$. 


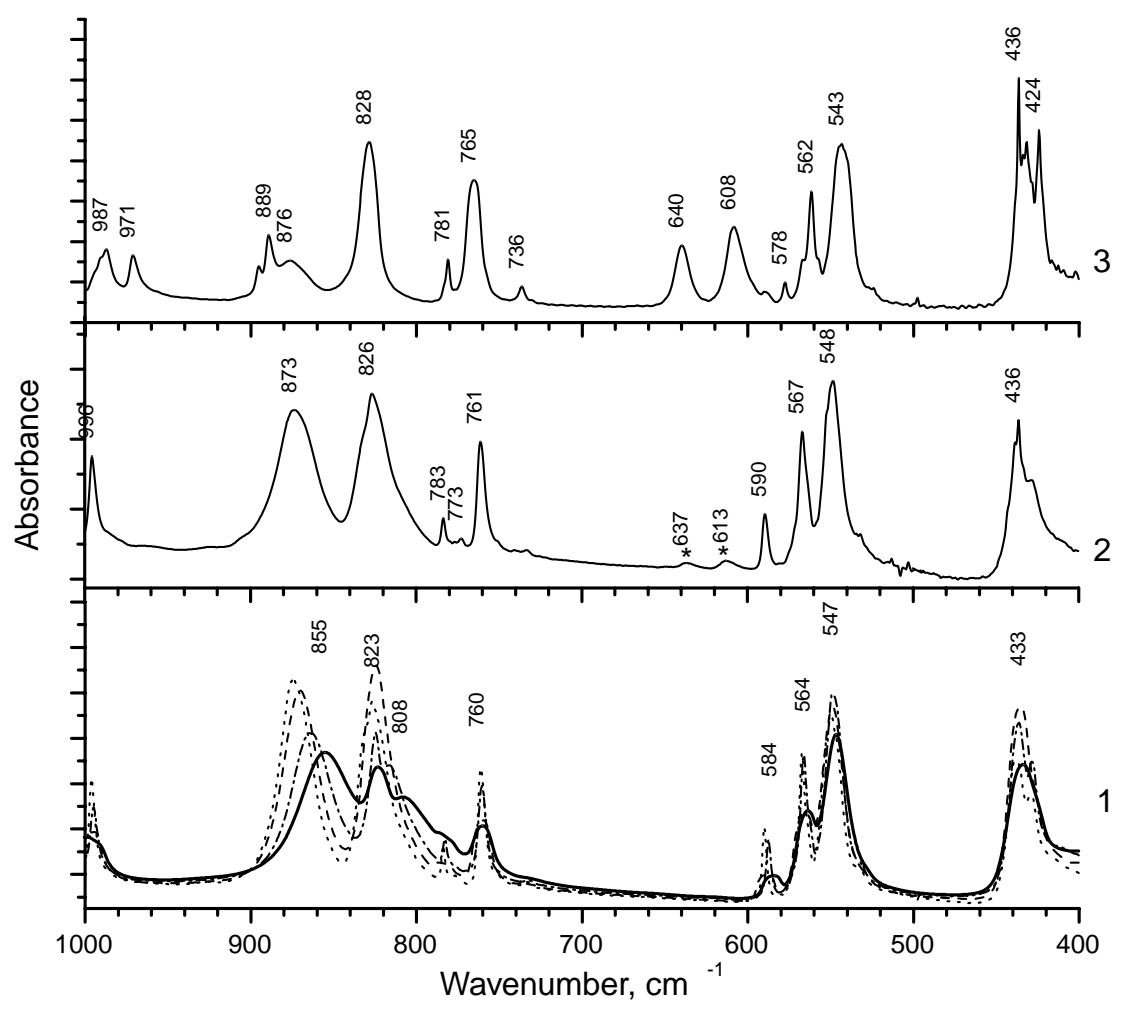

Fig. 7. FTIR spectra of uracil in the NH out of plane bending spectral region: $1-100 \% \mathrm{NH}$ at $300 \mathrm{~K}-$ solid; $200 \mathrm{~K}-$ dash-dots; $100 \mathrm{~K}-$ dashes; and $10 \mathrm{~K}$-dots; peak positions correspond to $300 \mathrm{~K}$ spectrum; 2-95\% NH at $10 \mathrm{~K} ;(*)$ bands of doped ND groups; 3-15\% NH at $10 \mathrm{~K}$.

There are four bands, which are considerably affected by cooling and show isotopic shifts close to the expected. The most intense bands for the pure NH crystal are observed at 873 and $828 \mathrm{~cm}^{-1}$ at $10 \mathrm{~K}$ (at room temperature these bands overlap extensively). The remaining two bands are weaker and appear at 590 and $567 \mathrm{~cm}^{-1}$. Note that the band observed at $808 \mathrm{~cm}^{-1}$ in the spectrum at $300 \mathrm{~K}$ undergoes a blue shift upon cooling and, at $10 \mathrm{~K}$, it appears merged with the intense skeletal band at $826 \mathrm{~cm}^{-1}$ (Fig. 7, frame 1) The complex shape of the band at ca. $826 \mathrm{~cm}^{-1}$, which results from the coalescence of the skeletal and $v_{4} \mathrm{NH}$ out of plane bending modes, can also be seen in the spectrum of the doped crystal where the amount of NH species is still ca. 95\% (Fig. 7, trace 2). In this spectrum, as well as in the spectrum of the mostly ND containing crystal (Fig. 7, trace 3), the $\mathrm{NH}$ bands at 873 and $826 \mathrm{~cm}^{-1}(10 \mathrm{~K})$ are related with their counterparts in the spectrum of ND-uracil appearing at 640 and $608 \mathrm{~cm}^{-1}$, respectively (with isotopic frequency ratios of ca. 1.36, which are similar to those found for out of plane vibrations in cytosine [6]). On the other hand, the counterparts of the remaining two bands exhibiting both cooling and isotopic sensitivity could not be detected, since they must be of low intensity and are with all probability overlapped with the intense skeletal bands appearing at ca. $430 \mathrm{~cm}^{-1}$.

The two intense bands can be unequivocally assigned to the out of plane $v_{4} \mathrm{~N} 3 \mathrm{H}\left(873 \mathrm{~cm}^{-1}\right)$ and $\mathrm{N} 1 \mathrm{H}$ (ca. $828 \mathrm{~cm}^{-1}$ ) modes, respectively, confirming the assignments suggested in [31]. A more detailed examination of the $900-750 \mathrm{~cm}^{-1}$ spectral region, however, reveals peculiarities which were not reported hitherto. The first one is that the intensity ratio of the $\mathrm{N} 3 \mathrm{H}$ and $\mathrm{N} 1 \mathrm{H} v_{4}$ bands is ca. 2:1. Indeed, contrary to the $v_{1}$ bands, whose intensity depends from their position (i.e., from the strength of the H-bond) and then their intensity ratios can only characterize the different proton ratios approximately, the intensity of the $v_{4}$ bands were shown $[3,4,32]$ to be independent of the H-bond strength and reflect the ratio of different protons in a crystal with accuracy not worse than $10 \%$. Since X-ray structural methods suggested that both $\mathrm{N} 1 \mathrm{H}$ and $\mathrm{N} 3 \mathrm{H}$ should be each one involved in a single $\mathrm{H}$-bond $[9,10]$, we would then expect an intensity ratio of the $\mathrm{N} 3 \mathrm{H}$ and $\mathrm{N} 1 \mathrm{H} v_{4}$ bands of ca. 1:1. A possible explanation for this contradiction will be provided later in this paper. The second is the different intensity ratios of the $v_{4} \mathrm{NH}$ and ND bands, which is clearly shown in the spectra presented in Fig. 7. As mentioned before, in the $900-750 \mathrm{~cm}^{-1}$ range of the spectrum of the pure $\mathrm{NH}$ uracil, the band contour at $300 \mathrm{~K}$ (Fig. 7, frame 1; solid line) shows one relatively narrow band at $823 \mathrm{~cm}^{-1}$, due to a skeletal mode, and at least two wide components at $855(40, \mathbf{3 4}) \mathrm{cm}^{-1}$ and $808(31, \mathbf{1 5}) \mathrm{cm}^{-1}$ (band widths and intensities, obtained by deconvolution are shown in parenthesis, the latter in bold type). The intensity ratio is ca. 2:1. The corresponding intensity ratio of the $v_{4}$ bands in ND-uracil (appearing at 625 and $590 \mathrm{~cm}^{-1}$ at $300 \mathrm{~K}$ ) is ca. 1:1. This value does not change at $10 \mathrm{~K}$ (see Fig. 7, trace 3). 


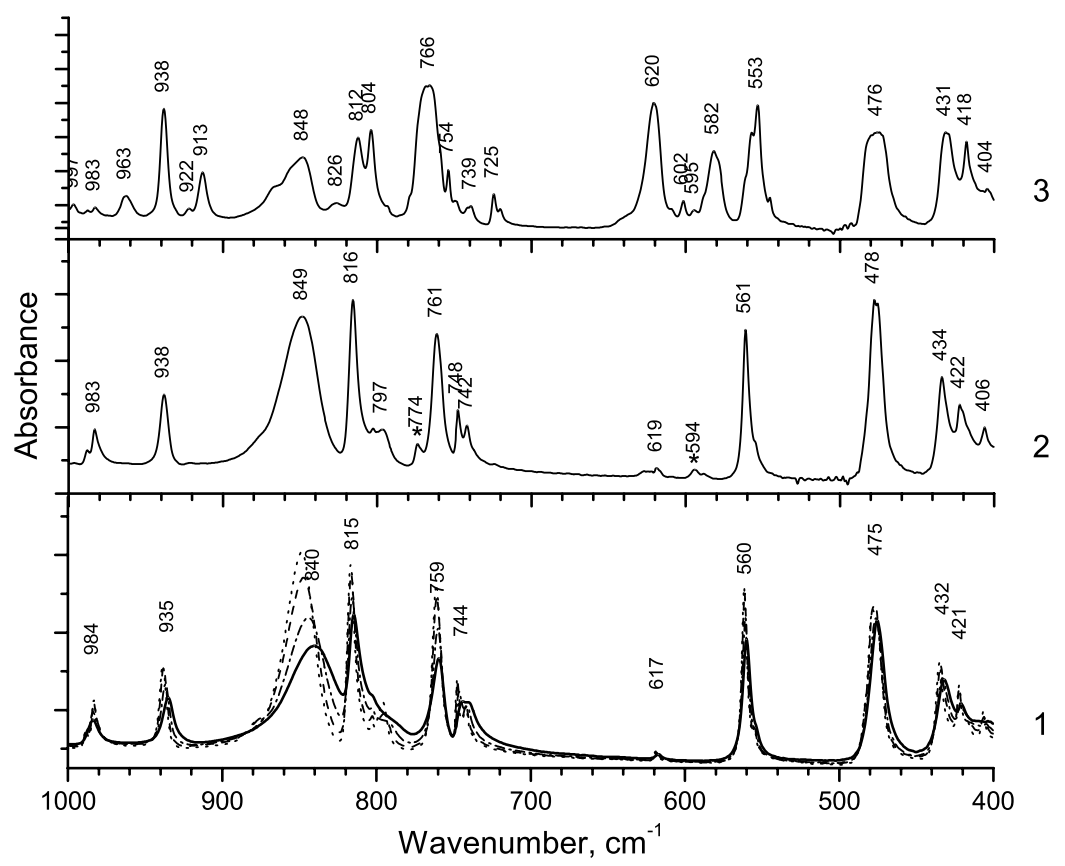

Fig. 8. FTIR spectra of thymine in the NH out of plane bending spectral region: $1-100 \%$ NH at $300 \mathrm{~K} —$ solid; $200 \mathrm{~K} —$ dash-dots; $100 \mathrm{~K}-$ dashes; and $10 \mathrm{~K}$-dots; peak positions correspond to $300 \mathrm{~K}$ spectrum; $2-95 \% \mathrm{NH}$ at $10 \mathrm{~K} ;(*)$ bands of doped ND groups; 3-20\% NH at $10 \mathrm{~K}$.

The structural changes occurring in uracil upon deuteration could be the most probable reason for different intensity ratio of the bands in NH- and ND-uracil (see below).

Other bands observed in the $1000-400 \mathrm{~cm}^{-1}$ region (see Fig. 7) do not show any remarkable changes with cooling and deuteration and should be assigned to skeletal modes.

3.1.3.2. Thymine. The spectra of all three samples of thymine are presented in Fig. 8 (traces 1, 2 and 3 belong to pure $\mathrm{NH}-, 95 \% \mathrm{NH}-$ and $20 \% \mathrm{NH}$-samples, respectively) and, in general, are similar to those previously reported $[23,30,33]$. The weak bands at 983,748 , and $742 \mathrm{~cm}^{-1}$ and the relatively strong bands at 849 and $816 \mathrm{~cm}^{-1}$ (in the spectrum of the pure $\mathrm{NH}$-sample obtained at $10 \mathrm{~K}$ ) are significantly sensitive to cooling and D-exchange. The intensities of these bands fall off at deuterium exchange, and new bands appear at $725,620,582,553$, and $551 \mathrm{~cm}^{-1}$ in the spectrum of ND-thymine (compare traces 1 and 3 of Fig. 8). The isotopic frequency ratios of these bands are 1.36, 1.37, 1.40, 1.35, and 1.35, respectively. All these bands should have significant contributions from $v_{4} \mathrm{NH}$ (or ND) coordinates.

In consonance with [33], our results unequivocally show that the $849 \mathrm{~cm}^{-1}$ band should be ascribed to the $v_{4}$ out of plane $\mathrm{N} 3 \mathrm{H}$ bending mode. The assignment of the second expected $v_{4}$ vibration was not straightforward, since the intensity of the corresponding band should not differ strongly from that of the $849 \mathrm{~cm}^{-1}$ band (the number of $\mathrm{N} 1 \mathrm{H}$ and $\mathrm{N} 3 \mathrm{H}$ groups is equal and in principle the intensity ratio expected for the $v_{4}$ bands due to these two groups is $1: 1$ ). A closer inspection of the $900-780 \mathrm{~cm}^{-1}$ spectral multiplet profile shows that, like in uracil, a relatively broad band centered at ca. $799 \mathrm{~cm}^{-1}$ is observed in the room temperature spectrum of thymine, with a relative intensity to the band at $842 \mathrm{~cm}^{-1}$ (which correlates with the band at $849 \mathrm{~cm}^{-1}$ in the spectrum at $10 \mathrm{~K}$ ) equal to $1: 2$. Upon cooling, this band splits due to participation in resonant interactions; one component shifts to higher frequency, merging with the skeletal band observed at $814 \mathrm{~cm}^{-1}$ at room temperature, while the others give rise to the bands observed at 803 and $797 \mathrm{~cm}^{-1}$.

The assignment of the $v_{4}$ N3D and N1D bands could be made straightforwardly to the bands at 620 and $582 \mathrm{~cm}^{-1}$, respectively; these two bands are narrow and well resolved and their assignment is absolutely clear. As in the case of the $v_{4} \mathrm{NH}$ bands, a $v_{4} \mathrm{~N} 3 \mathrm{D} / \mathrm{N} 1 \mathrm{D}$ intensity ratio of ca. 2:1 is observed for all temperatures studied.

Note that the nature of bands at 849 and $816 \mathrm{~cm}^{-1}$ was briefly discussed in [23] and these bands were there assigned to vibrations having only relatively modest contributions from the $\mathrm{N} 1 \mathrm{H}$ and $\mathrm{N} 3 \mathrm{H}$ out of plane coordinates (not more than 20-35\% PED). In [29], the band at $849 \mathrm{~cm}^{-1}$ was considered to be the result of the overlapping bands due to the out of plane $\gamma(\mathrm{C} 2=\mathrm{O})$ and $\gamma(\mathrm{C} 4=\mathrm{O})$ modes, while the band appearing at $816 \mathrm{~cm}^{-1}$ was ascribed to a skeletal ring mode. Also the bands observed at 582 and $551 \mathrm{~cm}^{-1}$ in the spectrum of ND-thymine (that correlate with those at 816 and $742 \mathrm{~cm}^{-1}$ in the spectrum of the non-deuterated thymine which, as mentioned above, should have significant contributions from the out of plane $\mathrm{NH}$ proton modes) were also miss-assigned to skeletal modes [29]. Our assignment then confirms the experimental and calculation results reported 
in [22] only in case of the $v_{4} \mathrm{~N} 3 \mathrm{H}$ band-its frequency was there estimated as being ca. $840-860 \mathrm{~cm}^{-1}$.

The present assignments are in agreement with the temperature and isotopic substitution behavior observed for all these bands. In addition, the similarity in behavior found for thymine and uracil is also consistent with structural data that indicate that the H-bond interactions in the crystals of the two compounds are similar [9-11].

\subsubsection{Summary of the main results extracted from the analysis of the spectra of uracil and thymine}

1. The $v_{1}$ bands of $\mathrm{N} 1 \mathrm{H}$ and $\mathrm{N} 3 \mathrm{H}$ groups in uracil are observed at 3106 and $3000 \mathrm{~cm}^{-1}$, respectively (at $10 \mathrm{~K}$ ). The corresponding N1D and N3D $v_{1}$ bands in ND-uracil could not be assigned precisely, being tentatively ascribed to the main components of the band with complex contour observed in the $2370-2200 \mathrm{~cm}^{-1}$ region.

2. The two $v_{4}$ bands of $\mathrm{N} 3 \mathrm{H}$ and $\mathrm{N} 1 \mathrm{H}$ protons in uracil are observed at 854 and $809 \mathrm{~cm}^{-1}$ at $300 \mathrm{~K}$ and at 873 and ca. $828 \mathrm{~cm}^{-1}$ at $10 \mathrm{~K}$, respectively. The intensity ratio of these bands is ca. 2:1 at all temperatures studied. This intensity ratio differs from that observed for the corresponding ND $v_{4}$ bands (which are observed respectively at 640 and $608 \mathrm{~cm}^{-1}$ in the spectra of ND-uracil at $10 \mathrm{~K}$ ), that is approximately $1: 1$ and equal to that expected on the basis of the available structural information obtained from X-ray diffraction $[9,10]$. The different intensity ratio of the bands in NH- and ND-uracil suggests that structural changes occur in uracil crystal structure upon deuteration and/or that different resonant effects are operating in the two samples.

3. The previously reported red shifts in $v_{1}\left[\mathrm{~N} 1 \mathrm{H}\left(370 \mathrm{~cm}^{-1}\right)\right.$ and $\left.\mathrm{N} 3 \mathrm{H}\left(375 \mathrm{~cm}^{-1}\right)\right]$ and blue shifts in $v_{4}[\mathrm{~N} 1 \mathrm{H}$ $\left(259 \mathrm{~cm}^{-1}\right)$ and $\left.\mathrm{N} 3 \mathrm{H}\left(231 \mathrm{~cm}^{-1}\right)\right]$, which were assigned to closed uracil dimers and measured in Ar matrix [16] using as reference data the frequencies for the matrixisolated monomer, are similar to those now measured in the cold crystal spectra (red shifts: $376 \mathrm{~cm}^{-1} \mathrm{~N} 1 \mathrm{H}$ and $433 \mathrm{~cm}^{-1} \mathrm{~N} 3 \mathrm{H}$; blue shifts $257 \mathrm{~cm}^{-1} \mathrm{~N} 1 \mathrm{H}$ and $191 \mathrm{~cm}^{-1} \mathrm{~N} 3 \mathrm{H}$ ). This result is a strong evidence of the structural importance of the dimeric units in the crystal of uracil, being in consonance with the available X-ray data $[9,10]$.

4. In the thymine spectrum the $\mathrm{N} 3 \mathrm{H}$ and $\mathrm{N} 1 \mathrm{H} v_{1}$ bands are not resolved at $300 \mathrm{~K}$, giving rise to the broad feature centered at $3024 \mathrm{~cm}^{-1}$; it could be suggested that at $10 \mathrm{~K}$ the $v_{1}$ bands of $\mathrm{N} 1 \mathrm{H}$ and $\mathrm{N} 3 \mathrm{H}$ protons correspond to the features observed at 3040 and $3008 \mathrm{~cm}^{-1}$, respectively. The $v_{1}$ bands of the N1D and N3D groups in deuterated thymine are observed at 2307 and $2271 \mathrm{~cm}^{-1}$ at $300 \mathrm{~K}$ and 2306 and $2277 \mathrm{~cm}^{-1}$ at $10 \mathrm{~K}$. The contour of the main bands was found to be complex at $10 \mathrm{~K}$. The isotopic frequency ratios for both vibrations were found to be ca. 1.32 , indicating a relatively high anharmonicity for these modes.
5. The $v_{4}$ bands of $\mathrm{N} 3 \mathrm{H}$ and $\mathrm{N} 1 \mathrm{H}$ protons of thymine are observed at 842 and ca. $799 \mathrm{~cm}^{-1}$, respectively (at room temperature). At $10 \mathrm{~K}, v_{4} \mathrm{~N} 3 \mathrm{H}$ is observed at $849 \mathrm{~cm}^{-1}$, while $v_{4} \mathrm{~N} 1 \mathrm{H}$ gives rise to a complex band with components at 816,803 , and $797 \mathrm{~cm}^{-1}$. In deuterated thymine the corresponding N3D and N1D $v_{4}$ bands are observed (at $10 \mathrm{~K}$ ) as narrow (ca. $10-11 \mathrm{~cm}^{-1}$ ) and well resolved bands at 620 and $582 \mathrm{~cm}^{-1}$. For both NH and ND crystals, the $v_{4} \mathrm{~N} 3 \mathrm{H} / \mathrm{N} 1 \mathrm{H}$ intensity ratio was found to be ca. 2:1; this intensity ratio differs from that expected on the basis of the available structural information, obtained from X-ray measurements [10,11].

The assignments here proposed for $v_{4}$ vibrations in the two molecules studied deserve an additional note. It is well known that the ability of IR and Raman spectroscopies for examination of $\mathrm{H}$-bond proton modes is considerably different, with the first method being much more sensitive to these vibrations than the latter. In general, scattering originating from H-bond proton modes is weak and very often the corresponding bands cannot be observed in Raman spectra. On the other hand, these vibrations give usually intense bands in infrared. Consequently, Raman spectra of condensed phases where H-bonds play an important role resemble more the Raman spectrum of the monomer than IR spectra of the condensed phase resemble the corresponding IR spectrum of the monomer. Indeed, as it was stated in [18], "Comparison of the Raman spectrum of thymine isolated in the Ar matrix with that of a polycrystalline sample indicates that they are quite similar, in marked contrast to the differences in the corresponding infrared spectra".

In consonance with the above information, all bands here ascribed to the $v_{4}$ vibrations are very weak or absent in the Raman spectra of uracil and thymine crystals both at $15 \mathrm{~K}$ or at room temperature [21-23,29]. Furthermore, it can be noticed from the comparison of the Raman spectra of uracil and thymine at $15 \mathrm{~K}$, presented in [21,23], that they are essentially different in the range below $1000 \mathrm{~cm}^{-1}$ (in all three spectral parameters: number of observed bands, peak positions and relative intensities), while the IR spectra of both solids are similar (compare traces 1 and 2 in Figs. 7 and 8). In particular, the most intense bands observed in this range for uracil $\left(873,827\right.$, and $\left.590 \mathrm{~cm}^{-1}\right)$ and thymine $(849,816$, and $561 \mathrm{~cm}^{-1}$ ) have similar frequencies and sensitivity to both $\mathrm{D}$-exchange and temperature variation (the relatively intense band at ca. $761 \mathrm{~cm}^{-1}$ in the spectrum of both compounds does not show the typical behavior of a proton mode regarding cooling and D-exchange-see Figs. 7 and 8 -and should be assigned, in consonance with $[29,33]$, to a skeletal mode. These results can only be explained if, as here considered, these intense IR bands that are absent (or very weak) in the Raman spectra belong to $v_{4}$ modes of differently $\mathrm{H}$ bond protons. The close peak positions of these bands in the spectra of the two compounds reflect the similarities of H-bonding interactions in the two crystals (and, consequently, of the energy associated with the different types of 
H-bonds found in both crystals). Note that in consonance with this interpretation, the H-bond distances obtained by $\mathrm{X}$-ray in both crystals are also very similar [9-11].

\subsection{Spectral parameters and hydrogen bonding: use of empirical correlations}

Once the assignment and accurate determination of peak positions of both $v_{1}$ stretching and $v_{4}$ out of plane bending $\mathrm{NH}$ mode bands could be undertaken, it is now possible to calculate the red shifts of $v_{1}$ and blue shifts of $v_{4}$ bands relatively to their position in the monomer and use these data to estimate their internal correlation and their correlation with the H-bond lengths and energies in the crystals of uracil and thymine; the latter results can be compared with independent thermodynamic data, since sublimation heats were previously measured experimentally for the studied crystals [34].

\subsubsection{Prediction of the $v_{4}$ bands positions from the red shift of $v_{1}$ : the abundance of different types of $H$-bond in uracil and thymine crystals}

The calculation of the shifts in the position of both $v_{1}$ and $v_{4}$ bands in the crystal state is made relatively to their frequency in the monomers obtained from matrix isolation spectroscopy $\left(v^{0}\right)$. Several matrix isolation studies on uracil and thymine are available, but in all those studies the peak positions of the relevant bands agree within the experimental error. The data reported for the two molecules (Ar matrix) in $[19,30]$ was here selected as reference data: for uracil, $(\mathrm{N} 1 \mathrm{H})$ group: $v_{1}^{0}=3482$ and $v_{4}^{0}=551 \mathrm{~cm}^{-1} ;(\mathrm{N} 3 \mathrm{H})$ group: $v_{1}^{0}=3433$ and $v_{4}^{0}=664 \mathrm{~cm}^{-1}$; for thymine, $(\mathrm{N} 1 \mathrm{H})$ group: $v_{1}^{0}=3480$ and $v_{4}^{0}=545 \mathrm{~cm}^{-1} ;(\mathrm{N} 3 \mathrm{H})$ group: $v_{1}^{0}=3434$ and $v_{4}^{0}=662 \mathrm{~cm}^{-1}$.

It was found [35] that the red shift of $v_{1}$ and the blue shift of $v_{4}$ bands associated with a given $\mathrm{H}$-bond proton correlate to each other as $\Delta v_{4}^{2}=2.5\left(\Delta v_{1}\right)^{1 / 2}-18$, where $\Delta v_{4}^{2} \equiv 10^{-4}\left[\left(v_{4}\right)^{2}-\left(v_{4}^{0}\right)^{2}\right]$ and $\Delta v_{1}$ is the red shift of the $v_{1}$ band (both $v_{1}$ and $v_{4}$ are expressed in wavenumbers). Using this empirical relationship, the $v_{4}$ frequencies in the crystal spectra of the two molecules were estimated from the observed red shifts of $v_{1}$. For uracil, the N1H red shift is $\Delta v_{1}=376 \mathrm{~cm}^{-1}$ and $v_{4}^{0}=551 \mathrm{~cm}^{-1}$; thus the $v_{4}(\mathrm{~N} 1 \mathrm{H})$ band in the uracil crystal, at $300 \mathrm{~K}$, can be estimated to occur at ca. $780 \mathrm{~cm}^{-1}$. Similarly, for the $(\mathrm{N} 3 \mathrm{H})$ group, $\Delta v_{1}=$ $433 \mathrm{~cm}^{-1}$, and the predicted position of $v_{4}$ in the room temperature spectrum of the crystal is ca. $880 \mathrm{~cm}^{-1}$. The estimated values are close to the two bands at observed at 808 and $855 \mathrm{~cm}^{-1}$ at $300 \mathrm{~K}\left(873\right.$ and $828 \mathrm{~cm}^{-1}$ at $\left.10 \mathrm{~K}\right)$ and indirectly confirm the assignments made in the previous section for both $v_{4}$ bands of $\mathrm{N} 1 \mathrm{H}$ and $\mathrm{N} 3 \mathrm{H}$ in the uracil crystal. Indeed, we can state that these two bands relate to the $v_{1}$ modes of the $\mathrm{N} 1 \mathrm{H}$ and $\mathrm{N} 3 \mathrm{H}$ groups, which reflect the two main $\mathrm{H}$-bond linkages present in the crystal, in agreement with the structural data obtained by X-ray $[9,10]$. The percentage of these H-bonds is proportional to the contribution of the relative intensity of these bands to the total intensity associated with bands ascribed to $v_{4}$ (which, as discussed before also include the bands observed at 590 and $567 \mathrm{~cm}^{-1}$ ), i.e., ca. $82 \%$ (with relative accuracy of $\sim 15 \%$ ). The observation of the bands at 590 and $567 \mathrm{~cm}^{-1}$, which are also strongly sensitive to temperature variation and D-exchange, reflects the presence in the crystal of disordered (in the sense of not presenting long range periodicity) $\mathrm{H}$-bonds. Such bonds, usually [1-7] are not observable in the $v_{1}$ stretching range and cannot be detected by structural methods (e.g., X-ray) due to the insensitivity of these latter methods to short range interactions (in opposition to their ability to deal with long range periodic ordering). The relative intensities of the 590 and $567 \mathrm{~cm}^{-1}$ bands to the total intensity associated with bands ascribed to $v_{4}$ lead to an estimated amount of associated $\mathrm{H}$-bonds of 5 and $13 \%$, respectively.

A similar estimation for thymine can be made using the values extracted from the spectrum at $10 \mathrm{~K}$ for $v_{1}$ (at room temperature, as described in the previous section, the two modes give rise to a single broad band centered at $\left.3024 \mathrm{~cm}^{-1}\right): 3040 \mathrm{~cm}^{-1}(\mathrm{~N} 1 \mathrm{H}) ; 3008 \mathrm{~cm}^{-1}(\mathrm{~N} 3 \mathrm{H})$. For this molecule, $v_{1}^{0}=3480, v_{4}^{0}=545$ and $\Delta v_{1}=440 \mathrm{~cm}^{-1}$ $(\mathrm{N} 1 \mathrm{H})$, corresponding to a predicted position for $v_{4}$ in the crystal of ca. $800 \mathrm{~cm}^{-1}$; for $\mathrm{N} 3 \mathrm{H}, v_{1}^{0}=3434, v_{4}^{0}=662$ and $\Delta v_{1}=426 \mathrm{~cm}^{-1}$, yielding a predicted frequency for $v_{4}$ of ca. $880 \mathrm{~cm}^{-1}$. The estimated frequencies for both $\mathrm{N} 1 \mathrm{H}$ and $\mathrm{N} 3 \mathrm{H}$ bands in the crystal are then in excellent agreement with the bands ascribed to these modes $\left(v_{4} \mathrm{~N} 1 \mathrm{H}: 799 \mathrm{~cm}^{-1}\right.$ and $v_{4} \mathrm{~N} 3 \mathrm{H}: 842 \mathrm{~cm}^{-1}$, at room temperature; $v_{4} \mathrm{~N} 3 \mathrm{H}$ : $873 \mathrm{~cm}^{-1}$, at $\left.10 \mathrm{~K}\right)$.

The contribution (relative intensity) of the bands at 842 and ca. $799 \mathrm{~cm}^{-1}$ to the total intensity associated with bands ascribed to $v_{4}$ is ca. $84 \%$. The other four bands in the thymine spectrum that are sensitive to temperature and deuteration (observed at 983, 748, and $742 \mathrm{~cm}^{-1}$ ) correspond to relative intensities (i.e., abundances) of ca. 3, 8, and 5\%, respectively, and are related to "disordered" $\mathrm{H}$-bonds with different bond strengths.

\subsubsection{Estimation of $H$-bond energies and $H$-bond contributions to sublimation heats in uracil and thymine crystals}

It has been shown that the $\mathrm{H}$-bond energy (in $\mathrm{kJ} \mathrm{mol}^{-1}$ ) and the red shift $\left(\Delta v_{1}\right.$, in $\left.\mathrm{cm}^{-1}\right)$ of $v_{1}$ bands obey the correlation $(\Delta H)^{2}=1.92\left[\left(\Delta v_{1}\right)-40\right]$ [28]. Using this relationship, the energies of the "ordered" H-bonds present in crystalline uracil and thymine can be estimated. For uracil, the calculated energies for the $\mathrm{N} 1 \mathrm{H}$ and $\mathrm{N} 3 \mathrm{H}$ groups $(-\Delta H)$ are 25.4 and $27.5 \mathrm{~kJ} \mathrm{~mol}^{-1}$ per one proton, respectively. From the alternative empirical correlation between the H-bond energy and the blue shift of the $v_{4}$ mode bands $\left(\Delta H=0.67 \Delta v_{4}^{2}\right.$, where $\Delta v_{4}^{2} \equiv 10^{-4}\left[\left(v_{4}\right)^{2}-\left(v_{4}^{0}\right)^{2}\right]$, $v_{4}$-in $\left.\mathrm{cm}^{-1}[3,32]\right)$ these energies can also be estimated, being 23.4 and $19.4 \mathrm{~kJ} \mathrm{~mol}^{-1}$, for $\mathrm{N} 1 \mathrm{H}$ and $\mathrm{N} 3 \mathrm{H}$, respectively. For thymine the corresponding estimations are 
necessarily less accurate due to larger uncertainties in the spectral data. For this molecule, the red shift correlation yields $-\Delta H=27.7 \mathrm{~kJ} \mathrm{~mol}^{-1}$ for $\mathrm{N} 1 \mathrm{H}$ and $27.2 \mathrm{~kJ} \mathrm{~mol}^{-1}$ for $\mathrm{N} 3 \mathrm{H}$, while the corresponding values extracted from the blue shift correlation are 22.9 and $18.1 \mathrm{~kJ} \mathrm{~mol}^{-1}$. Note that the values predicted on the basis of the two empirical correlations for $\mathrm{N} 3 \mathrm{H}$ differ significantly from each other for both molecules, the observed differences being considerably larger than the expected error. Though no definitive explanation for this discrepancy can be provided here, it may result, at least in part, from use of overestimated reference values for $v_{4}^{0} \mathrm{~N} 3 \mathrm{H}$. Indeed, these values were taken from matrix isolation data [19] and it is well known that under these experimental conditions specific matrix/solute interactions (e.g., those resulting from matrix packing constraints) might lead to increase the frequency of some out of plane bending vibrations relative to the free molecule.

The mean values for H-bond energies $(-\Delta H)$, calculated from the above data in uracil are ca. $24 \pm 5 \mathrm{~kJ} \mathrm{~mol}^{-1}$ for both $\mathrm{N} 1 \mathrm{H}$ and $\mathrm{N} 3 \mathrm{H}$ protons, while in thymine the corresponding values appear to be similar. These values are in reasonable agreement with independent thermodynamic data [34] - the binding energies of uracil and thymine dimers were measured as 19.8 and $18.8 \mathrm{~kJ} \mathrm{~mol}^{-1}$ per one H-bond, respectively, in the gas phase and, for uracil, $18.0 \mathrm{~kJ} \mathrm{~mol}^{-1}$ in an inert solvent [34]. Note that in the solid state, H-bonds are usually $20 \%$ stronger than in both the gaseous phase and inert solvent. The identical values of $-\Delta H$ in the crystals of the two compounds indicate similar H-bond networks and are also consistent with the already mentioned similarity of H-bond distances in both crystals [9-11].

Using a similar approach, the H-bond energies of "disordered" H-bonds could be estimated. For uracil, v 4 bands at 590 and $567 \mathrm{~cm}^{-1}$, correlate with energies of ca. 3 and $1 \mathrm{~kJ} \mathrm{~mol}^{-1}$, respectively. In the case of thymine, the $v_{4}$ bands at 983,748 , and $742 \mathrm{~cm}^{-1}$ correlate with energies of ca. 40,13 , and $12 \mathrm{~kJ} \mathrm{~mol}^{-1}$.

The above listed energies of all H-bonds present in the crystals, multiplied by their abundance, should reflect the $\mathrm{H}$-bonding contribution to sublimation heats of uracil and thymine. From available experimental data [34] it can be concluded that the differences between the sublimation heats of uracil and $N, N$-dimethyl-uracil and between thymine and $N, N$-dimethyl-thymine (which should reflect the H-bonding contribution in uracil and thymine crystals, respectively) are ca. 29 and $15 \mathrm{~kJ} \mathrm{~mol}^{-1}$. If the crystals were ideal and contained only the types of H-bonds accounted by their X-ray structures [9-11], which, as estimated above, correspond to $-\Delta H \sim 24 \mathrm{~kJ} \mathrm{~mol}^{-1}$ (per bond), this contribution should be ca. $48 \mathrm{~kJ} \mathrm{~mol}^{-1}$. On the other hand, the estimated value obtained taking into consideration all types of H-bonds revealed by the analysis of the $v_{4}$ spectral region in the present study is, for both compounds, ca. $35 \mathrm{~kJ} \mathrm{~mol}^{-1}$, thus improving the agreement with the experimental data obtained by an independent method [34]. These results give further support to our suggestion about the presence of additional "disordered" types of H-bonds, with different energies, besides those probed by X-ray.

\subsubsection{Possible explanation for the observed intensity ratio} 2:1 for the $v_{4}$ proton modes $\mathrm{N} 3 \mathrm{H} / \mathrm{N} 1 \mathrm{H}$ in uracil and thymine and estimation of $H$-bond distances from the $v_{1}$ red shift

As it was mentioned above, the presence of two different $\mathrm{H}$-bonded protons connecting the units of the cyclic $\mathrm{H}$ bonded dimers detected by X-ray in both uracil and thymine crystals, is expected to give rise to two infrared $v_{4}$ bands (one associated to each group), which should have nearly equal intensities, since it is well known that the intensity of $v_{4}$ mode bands is practically (within 10\%) constant and, in particular, does not depend from the H-bond energy [1-7]. To the best of our knowledge, violation of this rule has been reported only once [13]: namely, it was mentioned that the intensity ratio of the $\mathrm{N} 1 \mathrm{H}$ and $\mathrm{N} 3 \mathrm{H} v_{4}$ bands might decrease for high concentrations of matrix isolated uracil, suggesting a different level of involvement of the two groups in the inter dimer association. This observation was not explained in [13] and we believe that the explanation might be connected with our observation that the $v_{4}$ mode of the $\mathrm{N} 1 \mathrm{H}$ proton gives rise to a less intense band than expected on the basis of the crystal structure obtained by X-ray. A possible reason for the above mentioned findings might be the involvement of the $\mathrm{N} 1 \mathrm{H}$ proton in an additional H-bond. Indeed, the change of intensity can be correlated with a reduction of the effective charge at the proton, which, in turn, can occur if an additional electron donor is placed near the vibrating proton. The suggestion is that the $\mathrm{N} 1 \mathrm{H}$ proton of one molecule participates in a "bifurcated" $\mathrm{H}$-bond with two different carbonyl groups. The formation of the additional H-bond increases the frequency $(v)$ of the bending vibration of the proton and lessens its amplitude $(x)$ [in a first approximation $x \propto(v)^{-1 / 2}$ ] and, consequently, the corresponding band intensity. This explanation can also account for the complex structure noticed in some of the proton bands, especially at low temperature, by increasing the probability of existence of slightly different local spatial arrangements leading to slightly different H-bonds. In uracil, for example, the $\mathrm{N} 1 \mathrm{H}$ proton can establish a single $\mathrm{H}$-bond with one $\mathrm{O}=\mathrm{C} 4$ group (Fig. 9B) or, after a minor change in the interdimer distances, make an additional (bifurcated) H-bond with the $\mathrm{O}=\mathrm{C} 2$ group of a neighboring molecule (Fig. 9A). Note that, in fact, the suggested re-arrangement of H-bonds practically does not change the positions of the heavy atoms, thus being compatible, within the experimental error, with the available X-ray data.

The disruption of described "bifurcated" structure can be a reason for intensity ratio change of the $v_{4} \mathrm{~N} 1 \mathrm{H}$ and N3H bands at deuterium substitution in uracil spectra (see above).

Another intriguing inconsistency between the structural data and the results extracted from the infrared spectra appears when a comparison is made between the H-bond distances reported in the X-ray studies [9-11] and those estimated using the empirical correlation between these 

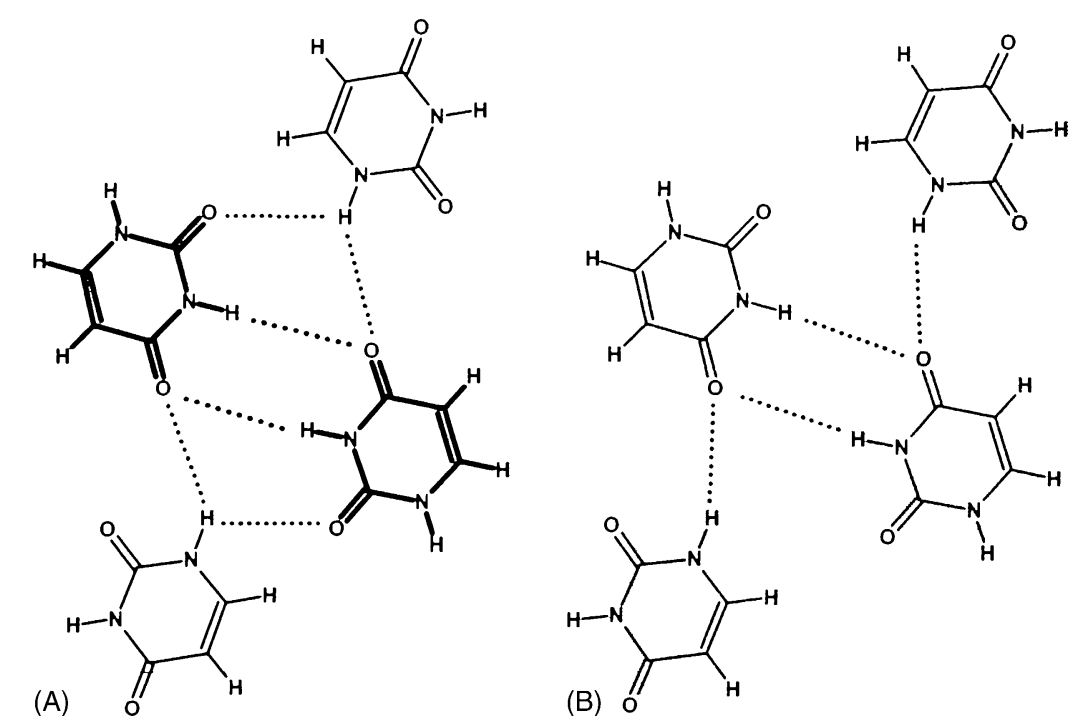

Fig. 9. (A) Possible alternative H-bond network for the same structural arrangement of uracil molecules, requiring only minor geometry changes in interdimer coordinates and (B) representation of the main structural unit of the uracil crystal, with H-bond network.

distances ( $r$, in nanometer) and the observed $v_{1}$ red shifts (in wavenumbers): $\Delta v_{1}=0.011 r^{-6.1}[1,2]$. The dominant $\mathrm{H}$-bond distances in uracil predicted using the red shifts/Hbond distance correlation (using the adequate temperature correction to the formula [4]) are $0.180(\mathrm{H} 1 \ldots \mathrm{O} 4)$ and $0.176 \mathrm{~nm}(\mathrm{H} 3 \cdots \mathrm{O} 4)$. In the room temperature spectra of thymine only one red shift was measured and the corresponding (average) H-bond length is estimated as $0.181 \mathrm{~nm}$.

On the other hand, using the data reported in the X-ray studies $[9,10](\mathrm{N} \cdots \mathrm{O}$ distances, together with $\mathrm{N} 3-\mathrm{H}$ and $\mathrm{N} 1-\mathrm{H}$ bond lengths, the latter being respectively 0.088 and $0.084 \mathrm{~nm}$ ) the $\mathrm{H}$-bond lengths in uracil can be obtained: $0.202 \mathrm{~nm}(\mathrm{H} 1 \cdots \mathrm{O} 4)$ and $0.198 \mathrm{~nm}(\mathrm{H} 3 \cdots \mathrm{O} 4)$. For thymine, $\mathrm{H} 1 \cdots \mathrm{O} 2$, and $\mathrm{H} 3 \cdots \mathrm{O} 2 \mathrm{H}$-bond lengths extracted from the X-ray data $[10,11]$ are 0.202 and $0.193 \mathrm{~nm}$, respectively.

When compared with the values estimated from the empirical correlation, the X-ray H-bond lengths are systematically larger by ca. $0.02 \mathrm{~nm}$; this deviation is $4-5$ times larger than the accuracy limits of the empirical correlation [2], which has been already successfully confirmed for more than 60 different hydrogen bonds. This discrepancy can, however, be solved if, instead of using the $\mathrm{N}-\mathrm{H}$ bond lengths given in the X-ray studies (which, as usually for X-ray data should be taken with care due to the difficulty of the method to precisely determine the position of hydrogen atoms), a different approach is used to obtain the H-bond lengths. In computational studies dedicated to the analysis of the crystal packing in uracil and its derivatives, the so-called "standard" $\mathrm{N}-\mathrm{H}$ bond length of $0.101 \mathrm{~nm}$ [36] was used. If this value is used together with the distances between the heavy atoms taken from the X-ray data [9-11], the H-bond lengths $[r(\mathrm{H} \cdots \mathrm{O})]$ reduce to $0.185 \mathrm{~nm}$ for uracil, and to $0.182(\mathrm{H} 1 \cdots \mathrm{O} 2)$ and $0.180 \mathrm{~nm}(\mathrm{H} 3 \cdots \mathrm{O} 2)$ for thymine, being practically identical (within the limits of the expected error of the correlation) to the estimated values obtained from the red shift/H-bond distance correlation.

\section{Conclusion}

This study demonstrates the utility of combining isotopic exchange techniques and cooling to low temperature to extract detailed information on H-bonding properties from infrared analysis of both $v_{1}$ and $v_{4}$ proton spectral regions of crystals with complex H-bonding networks. For the first time, observation and assignment of the infrared bands due to different types of $\mathrm{H}$-bonds present in the uracil and thymine crystals were undertaken. The bands of two imine proton stretching modes were identified in isotopically diluted samples at $10 \mathrm{~K}$. The number of observed uncoupled $\nu_{1}$ bands corresponds to the number of ordered H-bond contacts indicated by crystal structure analysis studies. However, our spectroscopic study reveals that the ordered contacts should represent only ca. $80-85 \%$ of the total amount of $\mathrm{H}$-bonds in the two crystals, as follows from the analysis of the $v_{4}$-mode spectral range. The remaining H-bonds correspond to "disordered" hydrogen bonds (in the sense of absence of the long range periodicity) that are not accessible to conventional structural methods such as X-ray diffraction. The H-bond energies estimated from empirical correlations from the infrared data agree well with independent thermodynamic experiments for cyclic dimers in both crystals and once again demonstrate the applicability of the empirical correlations here used to the study of complex $\mathrm{H}$-bonded networks. The total contribution of all H-bonds to the sublimation enthalpy of both solids, estimated from the present infrared results, was also found to reasonably agree with independent experimental thermodynamic data. On the other hand, the inconsistencies detected between the 
spectral and previously reported structural data, in particular those resulting from the detailed analysis of the $v_{4}$ spectral range, led us to propose a structural model for the H-bond network in the two crystals, where, in addition to the two $\mathrm{H}$-bonds revealed by $\mathrm{X}$-ray experiments, additional types of $\mathrm{H}$-bonds (including $\mathrm{N} 1-\mathrm{H}$ bifurcated ones) are considered; this model makes the spectroscopic and structural data consistent, improving the agreement between the two different sources of data.

\section{Acknowledgements}

M.R. gratefully acknowledges the financial support from the Israel Ministry for Immigrant Absorption; I.R. and R.F. acknowledge the financial support from Fundação para a Ciência e a Tecnologia, Lisbon (grant FCT \#SFRH/BPD/ 1661/2000 and research project POCTI/43366/QUI/2001).

\section{References}

[1] M. Rozenberg, C. Jung, G. Shocham, PCCP 5 (8) (2003) 1533-1535.

[2] M. Rozenberg, A. Loewenschuss, Y. Marcus, PCCP 2 (2000) 26992702.

[3] M. Rozenberg, A. Loewenschuss, H.-D. Lutz, Y. Marcus, Carbohydr. Res. 315 (1999) 89-97.

[4] M. Rozenberg, A. Loewenschuss, Y. Marcus, Carbohydr. Res. 328 (2000) 307-319.

[5] M. Rozenberg, G. Shoham, I. Reva, R. Fausto, Spectrochim. Acta 59A (2003) 3253-3266.

[6] M. Rozenberg, G. Shoham, I. Reva, R. Fausto, Spectrochim. Acta 60A (2004) 463-470.

[7] M. Rozenberg, in: E. Benedetti, C. Pedone (Eds.), Peptides 2002, Proceedings of the 27th European Peptide Symposium, Sorrento, Italy, Edizione Ziino, 2002, p. 872.

[8] A. Jeffrey, W. Saenger, Hydrogen Bonding in Biological Structures, Springer, Berlin, 1991.

[9] R.F. Stewart, L.H. Jensen, Acta Cryst. 23 (1967) 1102-1105.

[10] G. Portalone, L. Bencivenni, M. Colapietro, A. Pieretti, F. Ramondo, Acta Chim. Scand. 53 (1999) 57-68.

[11] K. Ozeki, N. Sakabe, J. Tanaka, Acta Cryst. B25 (1969) 1038-1045.
[12] P. Colarusso, K. Zhang, B. Guo, P.F. Bernath, Chem. Phys. Lett. 269 (1997) 39-48.

[13] L. Bencivenni, F. Ramondo, A. Pieretty, N. Sanna, J. Chem. Soc., Perkin Trans. 2 (2000) 1685-1693.

[14] A.Y. Ivanov, A.M. Plokhotnichenko, E.D. Radchenko, G.G. Sheina, Y.P. Blagoi, J. Mol. Struct. 372 (1995) 91-100.

[15] A.J. Barnes, M.A. Stuckey, L.L. Gall, Spectrochim. Acta 40A (1984) 419-431.

[16] G. Maes, M. Graindourze, J. Smets, J. Mol. Struct. 248 (1991) 89 110.

[17] M. Graindourze, J. Smets, T.H. Zeegers-Huyskens, G. Maes, J. Mol. Struct. 222 (1990) 345-364.

[18] K. Szczepaniak, M.M. Szczesniak, W. Person, J. Phys. Chem. A104 (2000) 3852-3863.

[19] M. Nowak, J. Mol. Struct. 193 (1989) 35-49.

[20] A. Les, L. Adamowicz, M.J. Nowak, L. Lapinski, Spectrochim. Acta 48A (1992) 1385-1395.

[21] A. Aamouche, M. Ghomi, C. Coulombeau, H. Jobic, L. Grajcar, M.H. Baron, V. Baumruk, P.Y. Turpin, C. Henriet, G. Berthier, J. Phys. Chem. 100 (1996) 5224-5234.

[22] M. Aida, M. Kaneko, M. Dupuis, T. Ueda, K. Ushizawa, G. Ito, A Kumakura, M. Tsuboi, Spectrochim. Acta A53 (1997) 393-407.

[23] A. Aamouche, M. Ghomi, C. Coulombeau, L. Grajcar, M.H. Baron, H. Jobic, G. Berthier, J. Phys. Chem. A101 (1997) 1808-1817.

[24] I.R. Gould, M.A. Vincent, I.H. Hiller, J. Chem. Soc., Perkin Trans. 2 (1992) 69-71.

[25] M. Nowak, K. Szczepaniak, M.M. Szczesniak, W. Person, J. Phys. Chem. A104 (2000) 3852-3863.

[26] V.K. Rastogi, C. Singh, V. Jain, M.A. Palafox, J. Raman Spectrosc. 31 (2000) 1005-1012.

[27] A.V. Iogansen, M.S. Rozenberg, J. Appl. Spectrosc. (USSR) 9 (1968) $1027-1030$

[28] A.V. Iogansen, Spectrochim. Acta A55 (1999) 1585-1612.

[29] S.L. Zhang, K.H. Michaelian, G.R. Loppnow, J. Phys. Chem. A102 (1998) 461-470

[30] M. Szczesniak, M.J. Nowak, H. Rostkowska, K. Szczepaniak, W. Person, D. Shugar, J. Am. Chem. Soc. 105 (1983) 5969-5976.

[31] J. Bandekar, G. Zundel, Spectrochim. Acta 38A (1982) 815-819.

[32] M. Rozenberg, A.V. Iogansen, A.A. Mashkovsky, S.E. Odinokov, Spectrosc. Lett. 5 (1972) 75-80.

[33] M. Mathlouthi, A.-M. Seuvre, J.L. Koenig, Carbohydr. Res. 134 (1984) 23-80.

[34] I.K. Yanson, A.V. Teplitsky, L.F. Sukhodub, Biopolymers 18 (1979) 1149.

[35] M.Sh. Rozenberg, Spectrochim. Acta A52 (1996) 1559-1563.

[36] S.L. Price, K.S. Wibley, J. Phys. Chem. A101 (1997) 2198-2206. 